This is an author produced version of a paper published in Hydrological Processes. This paper has been peer-reviewed but does not include the final publisher proof-corrections or journal pagination.

Citation for the published paper:

Seibert, J., Rodhe, A. and Bishop, K. (2003) Simulating interactions between saturated and unsaturated storage in a conceptual runoff model.

Hydrological Processes. 17:2, 379-390, ISSN: 0885-6087. http://dx.doi.org/10.1002/hyp.1130

Access to the published version may require journal subscription.

Published with permission from: John Wiley \& Sons, Ltd

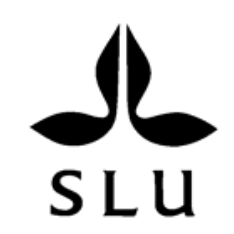

Epsilon Open Archive http://epsilon.slu.se 
Revised manuscript for the Special Issue of HP: Workshop on Runoff Generation and Implications for River Basin Modelling, 9-12 October 2000 in Freiburg

\title{
Simulating interactions between saturated and unsaturated storage in a conceptual runoff model
}

\author{
Jan Seibert ${ }^{1,3}$, Allan Rodhe ${ }^{2}$ and Kevin Bishop ${ }^{1}$
}

\footnotetext{
${ }^{1}$ Swedish University of Agricultural Sciences, Department of Environmental Assessment, S-750 07 Uppsala, Sweden

${ }^{2}$ Uppsala University, Institute of Earth Sciences, Hydrology, S-752 36 Uppsala, Sweden

${ }^{3}$ on leave from: Oregon State University, Department of Forest Engineering, Corvallis, OR 97331, U.S.A.
}

Corresponding author:

Jan Seibert

Swedish University of Agricultural Sciences

Department of Environmental Assessment

Box 7050

S-750 07 Uppsala

Sweden

e-mail: jan.seibert@ma.slu.se

Tel.: + 46-18-67 3145

Fax : +46-18-67 3156 


\section{Abstract}

There is an increasing demand for modelling the fluxes of chemical constituents at the catchment scale. Conceptual runoff models provide a basis for such modelling tasks provided that they capture the essential hydrological processes. However, most conceptual models do not fully address interactions between unsaturated and saturated storage. This can lead to unrealistic simulations for watersheds with shallow groundwater, where a large part of the soil volume can contribute to both the unsaturated and the saturated storage depending on groundwater levels. Adding a small amount of water to the saturated storage will cause a significant amount of water stored in the unsaturated zone to change its status to 'saturated'. The maximum volume of the unsaturated storage also decreases with rising groundwater levels, i.e., increasing saturated storage. In this study, a new model concept was proposed in which special emphasis was put on the interaction between saturated and unsaturated storage. The total storage was divided into two compartments, representing saturated and unsaturated storage, with a boundary moving up and down in response to the water budget of the compartments. Groundwater dynamics show a distinct pattern along the studied hillslope. Groundwater levels in an area close to the stream had dynamics similar to runoff, whereas levels further upslope responded to rainfall with a delay. To represent these differences in the model, the hillslope was subdivided into a riparian and an upslope reservoir. The performance of the new model was compared to that of simpler model variants without spatial differentiation and with or without the new formulation allowing for interactions between unsaturated and saturated storage. The new model approach provided the best results for simulating both runoff and groundwater dynamics. The subdivision of the hillslope accounted for most of the 
performance increase. To further test the model structure, ${ }^{18} \mathrm{O}$-concentrations in the stream were simulated and compared to measured values.

\section{Keywords}

Conceptual modelling, hillslope hydrology, saturated-unsaturated zones interactions, water storage, ${ }^{18} \mathrm{O}$

\section{Introduction}

Traditionally, conceptual runoff modelling has focused on the quantification of water flux at the catchment scale. In recent years, however, environmental problems have provided additional impetus for hydrological models to serve as the foundation of biogeochemical models. Runoff models must meet new requirements and be formulated in such a way as to address the specific demands made upon the model structure for modelling transport of chemical constituents. Correct simulations of internal variables such as groundwater levels and a realistic simulation of the interactions between saturated and unsaturated zone become essential, especially for hydrochemical processes where the soil-gas atmosphere is of importance.

Whenever shallow groundwater tables rise a significant part of the stored water changes its status from 'unsaturated' to 'saturated'. The process is reversed when these groundwater tables fall. In order to satisfy the continuity conditions for the mass flow of water (and chemical constituents) this interaction between saturated and unsaturated storage has to be taken into account. Furthermore, the available space for unsaturated storage depends on the saturated storage, because higher groundwater tables leave less soil volume for the unsaturated zone. Therefore, the total volume of the unsaturated storage can decrease even when the water content per unit soil volume increases. Bishop et al. (1998) calculated water storage in a small watershed based on groundwater-level observations, soil depths and soil characteristics (for the different 
soil horizons). They estimated that addition of $40 \mathrm{~mm}$ of rainfall could increase the saturated zone storage by over $100 \mathrm{~mm}$ (with a corresponding decrease of ca. $60 \mathrm{~mm}$ in unsaturated zone storage).

The significance of the interaction between the groundwater zone and soil water zone (defined here as the unsaturated part of the root zone) depends on the depth to the groundwater table. Three levels of interdependency can be identified:

1. If the groundwater table is comparatively deep (several meters) the connection is unidirectional, with groundwater recharge taking place during periods with high water content in the soil water zone. The soil water content is independent of the groundwater level. In this situation traditional conceptual model approaches that do not allow for soilwater - groundwater interactions are appropriate.

2. With decreasing depth to the groundwater table there is an increasing interaction. As the groundwater table approaches the lower boundary of the root zone, the water in this zone moves to establish hydrostatic equilibrium with the groundwater table. A high groundwater table gives high soil water content, and only a small amount of infiltration is needed to give groundwater recharge. Still the vertical extension of the soil water zone may be assumed to be constant over time, but the unsaturated storage at field capacity depends on the depth of the groundwater table. In this situation allowing for a capillary upward flow might be suitable for reasonable simulations. 3. With a very shallow groundwater table ( $<$ about $1 \mathrm{~m}$ ), as in the hillslope in the present study, the interaction becomes very strong. The groundwater table strongly influences the water content in the unsaturated part of the root zone and the groundwater table represents a moving boundary between saturated and unsaturated conditions. The latter results in a continuous transformation of root zone water 
between unsaturated and saturated conditions, with a rise in the groundwater table leading to a decrease in unsaturated soil water storage.

In the first two cases the unsaturated and saturated storages will be positively correlated whereas they will be negatively correlated in the third case. Traditional conceptual models, such as the HBV model (Bergström, 1995) or TOPMODEL (Beven et al., 1995), are not capable of simulating the latter case, i.e., a decreasing unsaturated storage with increasing saturated storage. The inability to correctly distinguish between the two different storages may hinder the use of the hydrological model as a foundation for the simulation of hydrochemical processes. One solution would be the use of a physically-based model based on, for instance, several soil layers and Richards' equation. The step from a conceptual to a physically-based model, however, might not be attractive because of the problems associated with physically-based models such as large data requirements, over-parameterisation and computational burden. In this study we chose to keep the simple conceptual modelling approach, but to introduce a more reasonable formulation for the interactions of the saturated and unsaturated zones.

Another problem with many conceptual models is caused by the simplified description of the relationship between groundwater storage and runoff. These models typically depict a catchment using a number of storages. One (or more) of them usually represents groundwater storage and thus can be related to groundwater levels. In most conceptual runoff models an unambiguous, monotonic function between the groundwater storage and runoff is implemented. Consequently, the dynamics of the simulated runoff from the groundwater zone always follows the simulated rise and fall in groundwater levels. 
TOPMODEL (Beven et al., 1995) is one example of such a model. TOPMODEL allows simulation of spatially distributed groundwater levels using a topographic index. These groundwater levels, however, always go up and down in parallel, and the mean groundwater level determines the simulated runoff from the groundwater zone. In other words, it is assumed that the spatially distributed groundwater levels and runoff can be described as a succession of steady state conditions. Sloan (2000) demonstrated that a single-valued storage-runoff relation might not be appropriate at the catchment scale. Allowing for a transient groundwater storage, and thus the simulation of a non-steady state relation between catchment water storage and runoff, is more realistic than assuming steady state.

When pursuing model approaches that allow for spatial distribution, it is highly desirable to compare the simulations with observed data for more variables than just runoff in order to ensure internal consistency (Seibert, 1999). The additional information from using groundwater-level data in different hillslope positions depends on the correlation between these levels and runoff. Groundwater levels from wells with a response different from that of runoff provide more new information than groundwater levels with dynamics similar to runoff. However, to be able to make most use of the additional information, a model must allow for differences between runoff and groundwater dynamics in some parts of the catchment. In this study, we formulated a conceptual model for hillslope runoff in which the interaction between saturated and unsaturated storage is taken into account. The model was tested on a hillslope where detailed groundwater level observations had revealed different groundwater dynamics in the upper and lower parts of the hillslope (Seibert et al., 2001). We thus formulated a two-box runoff model. The boxes represent the hillslope as two zones: an upper (upslope) and a lower (riparian) zone. 
Within each box there is a moving boundary between the saturated and unsaturated zone that represents the groundwater table. The runoff model was extended to simulate the flow of ${ }^{18} \mathrm{O}$ in order to test the model structure and to see whether calibration against ${ }^{18} \mathrm{O}$ could reduce parameter uncertainty.

\section{Material and Methods}

\section{Study site}

The Svartberget catchment is located in northern Sweden $60 \mathrm{~km}$ northwest of the city of Umeå (64 $\left.14^{\prime} \mathrm{N}, 10^{\circ} 46^{\prime} \mathrm{E}\right)$. The $0.50 \mathrm{~km}^{2}$-catchment is covered by mature Norway spruce and Scots pine. The groundwater data used in this study were collected along a $120 \mathrm{~m}$ long hillslope with a maximum height difference of 8 meters (Fig. 1). The sandy till soils have a porosity of 0.3 to 0.5 . Saturated hydraulic conductivity is on the order of $2 \cdot 10^{-5} \mathrm{~m} \mathrm{~s}^{-1}$ for the upper soil layer and typically decreases with depth below the ground surface (Bishop, 1991). Runoff from the hillslope was computed as the difference in discharge between the weirs above and below the hillslope ( 200 meters of stream reach, weirs B and C, Fig. 1).

Groundwater and streamwater levels were measured manually 1-7 times a day, with the more intense measurements during runoff events. Rainfall was measured and sampled for ${ }^{18} \mathrm{O}$ in a clearing one $\mathrm{km}$ from the hillslope, with the same frequency as the other observations. Streamwater was sampled for ${ }^{18} \mathrm{O}$ at several weirs along the stream, and the $\delta^{18} \mathrm{O}$ of the hillslope runoff was calculated from mass budget considerations for the stream using the $\delta^{18} \mathrm{O}$-values and stream discharge of weirs upstream and downstream from the hillslope. In order to reduce the error in the calculated $\delta^{18} \mathrm{O}$-values, the two most distant weirs (catchment area 0.19 and $0.5 \mathrm{~km}^{2}$ respectively, weirs A and E, Fig. 1) were used in these calculations. The $\delta^{18} \mathrm{O}$ of 
hillslope runoff was thus assumed constant along the stream reach delimited by these sampling points.

\section{Model description}

A conceptual model for hillslope runoff with interacting soil water and groundwater was developed based on the observation by Seibert et al. ( 2001) that two reservoirs accounted for the different dynamics of the riparian and upslope groundwater (Fig. 2). The hillslope is subdivided into two zones with a certain fraction, $f_{\text {riparian }}$, representing the riparian zone as has been done in models such as BICK (Eshleman, 1985), or in modifications of the HBV model (Bergström and Lindström, 1992). Modelled runoff is determined by the groundwater storage in the riparian reservoir, which is fed by local percolation and lateral flow from the upslope reservoir. No lateral flow is assumed to take place from the unsaturated reservoirs.

With the shallow groundwater in the hillslope under study (groundwater levels 0 $1.5 \mathrm{~m}$ below the ground surface) the interaction between saturated and unsaturated storage is important. The soil layer can be conceptualised as a column with two compartments, unsaturated and saturated, separated by a fully permeable boundary, the groundwater table. The boundary moves up and down in response to the water budget of the compartments. When the groundwater table rises, the thickness of the unsaturated zone decreases, making less space available for unsaturated storage and vice versa. Furthermore, a rise of the groundwater levels causes a portion of the water stored in the unsaturated zone to become part of the saturated storage. When the groundwater levels fall, a portion of the water that was stored in the saturated zone will become part of the unsaturated zone. In order to account for this effect of the groundwater level on the unsaturated water storage and to maintain the mass balance for water, the total groundwater reservoir (above a certain reference level in the 
ground) has to be considered rather than the dynamic storage normally used in flow modelling. The dynamic storage represents the drainable water amount and this is only a portion of the total water amount in the saturated zone. When isotope flow and storage are modelled it is also necessary to use the total groundwater storage, rather than the drainable part of this storage, as a mixing reservoir. In a similar manner, the unsaturated reservoir should contain all water in the unsaturated zone, not just water above the wilting point. In the following discussion the term storage always refers to total storage.

The maximum amount of saturated storage, $S_{\max }$, (with the groundwater table reaching the ground surface) is used as model parameter (see Table 1 for a list of all model parameters). Based on the calculated actual value of the saturated storage, $S$, the maximum unsaturated storage, $U_{\max }$, is computed (Eq. 1). Similarly the amount of water stored in the unsaturated zone below wilting point, $U_{\min }$, is computed (Eq. 2).

$$
\begin{aligned}
& U_{\text {max }}=c\left(S_{\text {max }}-S\right) \\
& U_{\text {min }}=d\left(S_{\text {max }}-S\right)
\end{aligned}
$$

$S, U$ and $U_{\min }$ represent volumes of water per unit ground area, whereas the model parameters $c$ and $d$ are dimensionless. From equations 1 and 2, it follows that $c$ corresponds to field capacity divided by porosity and $d$ corresponds to wilting point divided by porosity.

For the unsaturated zone, an approach similar to that used in the HBV model (Bergström, 1995) was chosen. The amount of rainfall, $P$, is divided into recharge to groundwater, $R$, and addition to the storage in the unsaturated zone using a non-linear function (Eq. 3, $\beta$ [-] is a shape factor). Evaporation from the soil, $E_{a c t}$, is estimated 
based on the actual storage in the unsaturated zone, $U$, and the potential evaporation, $E_{p o t}(\mathrm{Eq} 4)$.

$$
\begin{aligned}
& R=P\left(\frac{U-U_{\min }}{U_{\text {max }}-U_{\min }}\right)^{\beta} \\
& E_{\text {act }}=E_{p o t} \frac{U-U_{\min }}{U_{\max }-U_{\min }}
\end{aligned}
$$

Runoff is computed from the saturated storage in the riparian box by two linear equations, one of which is active only when the storage is above a certain threshold value, $S_{\text {threshold }}($ Eq. 5). The use of this equation is motivated by the observed increase of saturated hydraulic conductivity towards the ground surface (Bishop, 1991; Bishop et al., 1995).

$$
Q_{\text {riparian }}=k_{1} S+\max \left(0, k_{0}\left(S-S_{\text {threshold }}\right)\right)
$$

The flow from the upslope box to the riparian box is computed by a linear equation

$$
Q_{\text {upslope }}=k_{2} S
$$

Based on the equations above, the amount of unsaturated and saturated storage in each box is updated for each time step.

In the case of falling groundwater levels a certain amount of saturated storage changes its status to unsaturated. The change of storage in the saturated zone $(\Delta S)$ equals the difference between recharge (for the riparian box including lateral inflow from the upslope box) and runoff plus a portion of the change, which is the amount of water changing its status from saturated to unsaturated (Eq. 7). Eq. 7 can be rearranged to allow direct calculation of $\Delta S$ (Eq. 8) and computation of the corresponding change in unsaturated storage due to groundwater level change, $\Delta U_{g c}$ (Eq. 9).

$\Delta S=R-Q+c \Delta S$ 


$$
\begin{gathered}
\Delta S=\frac{R-Q}{1-c} \\
\Delta U_{g c}=-c \Delta S
\end{gathered}
$$

When the groundwater level rises, an amount of unsaturated storage in a similar way alters its status to 'saturated' (Eq.s 10-12).

$$
\begin{aligned}
& \Delta S=R-Q+c \frac{U}{U_{\text {max }}} \Delta S \\
& \Delta S=\frac{R-Q}{1-c \frac{U}{U_{\text {max }}}} \\
& \Delta U_{g c}=-c \frac{U}{U_{\max }} \Delta S
\end{aligned}
$$

The fraction $U / U_{\max }$ appears in these equations since drainage equilibrium ( $\left.U=U_{\max }\right)$ cannot be postulated when the groundwater table rises. When the groundwater table falls, on the other hand, drainage equilibrium can be expected in the drained soil layer and $U / U_{\max }=1$ (Eqs. 7-9).

The $\delta^{18} \mathrm{O}$ of hillslope runoff is simulated based on the calculated ${ }^{18} \mathrm{O}$-fluxes between the different saturated and unsaturated storages. In order to keep the number of model parameters low all rainfall is assumed to mix completely with the unsaturated storage and the $\delta^{18} \mathrm{O}$ of the groundwater recharge thus equals that of the unsaturated storage, following the logic of Harris et al. (1995). The assumption of complete mixing is only a first approximation, but it is partly justified by the shallow groundwater and its interaction with the soil water, which prevents the development of layered $\delta^{18} \mathrm{O}$ profiles. The concentration of the outflow from the upslope box equals the concentration of the saturated storage. In the riparian box different $\delta^{18} \mathrm{O}$-values were computed for the saturated storage above and below the threshold level, $S_{\text {threshold, }}$ with 
only limited mixing between those two parts. The volume of water from the lower part which was replaced by water from the upper part, $v_{\text {replace, }}$ was computed based on the runoff from the lower outflow, $q_{\text {lower }}$, and the storage above the threshold, $S$ $S_{\text {threshold }}$ (Equation 13) using one parameter, $p_{\text {replace }}[-]$.

$v_{\text {replace }}=q_{\text {lower }}+p_{\text {replace }}\left(S-S_{\text {threshold }}\right)$

The assumption behind this equation is that (1) the water flowing out of the lower outflow is replaced by water from above and (2) additional mixing is proportional to the amount of water stored above the threshold value. The $\delta^{18} \mathrm{O}$ of the runoff equals the runoff-weighted mean of these two parts of the riparian groundwater storage. The model was run with a time step of three hours for two summer periods (1986 and 1987). More ${ }^{18} \mathrm{O}$ data were available for the first period whereas more groundwater level data were collected during the second period. The model was calibrated simultaneously against observed runoff, groundwater levels and streamwater $\delta^{18} \mathrm{O}$ using a genetic algorithm (Seibert, 2000). For groundwater levels, mean time series were computed for both the riparian zone, based on observations from 30 wells, and the upslope zone, based on observations from 7 wells. The objective function was the arithmetic mean of $R_{\text {eff, }}, R_{\text {eff, log }}, r_{\text {spear }}$ and $R_{\text {eff,O-18, }}$, where $R_{\text {eff }}$ is the model efficiency (Nash and Sutcliffe, 1970) for runoff, $R_{\text {eff,log }}$ is the model efficiency computed from logarithmic runoff values, $r_{\text {spear }}$ is the Spearman rank correlation coefficient for the groundwater simulations (geometric mean of both zones) and $R_{e f f, O-18}$ is the model efficiency for streamwater $\delta^{18} \mathrm{O}$. Once a relatively good fit was obtained for the streamwater $\delta^{18} \mathrm{O} R_{e f f, O-18}$ was not sensitive even if better and poorer fits of the streamwater $\delta^{18} \mathrm{O}$ simulations could be distinguished visually. Therefore, minor 
manual parameter changes guided by visual inspection of the streamwater- $\delta^{18} \mathrm{O}$ fit were allowed after the automatic calibration.

The performance of the new model was compared to that of three model variants with different combinations of spatial differentiation and relation between unsaturated and saturated storage. The simplest variant (lumped and no coupling) corresponds to the HBV model. The other variants were the coupled saturated-unsaturated formulation with only one (lumped) box and the non-coupled (HBV) formulation with separate riparian and upslope boxes. The model variants were calibrated using two different evaluation criteria: a) $\left(R_{\text {eff }}+R_{\text {eff log }}\right) / 2$, and b) $\left(R_{\text {eff }}+R_{\text {eff log }}+r_{\text {spear }}\right) / 3$. In both cases a value of 1 corresponds to a perfect fit.

\section{Results}

The model could be successfully calibrated to simulate runoff (Fig.3) and groundwater levels (Fig. 4). The model efficiency was 0.92, and the mean rank correlation between simulated groundwater storage and observed mean groundwater levels was 0.94 . The decrease of unsaturated storage during events (Fig. 3) is a result of the coupled formulation of saturated and unsaturated storage. The relationship between observed groundwater levels and simulated saturated storage was linear for the upslope zone, but non-linear for the riparian zone (Fig. 4).

The simulations of streamwater $\delta^{18} \mathrm{O}$ were not fully satisfactory with a model efficiency of 0.51 . The model was able to reproduce the general trends but missed some short-term variations (Fig. 5). For the small event on 24 August 1986 (Fig 5), for instance, the simulated $\delta^{18} \mathrm{O}$ increased sharply while the observations showed a slight decrease.

The performance for different model variants showed that the new formulation improved results (Table 2). For the runoff and groundwater simulations, subdivision 
of the hillslope into two boxes accounted for most of the improvement while the coupling of unsaturated and saturated storage had only minor effects on model performance.

\section{Discussion}

To date, unsaturated and saturated storage have usually been represented separately in conceptual runoff models, i.e., the amount of water in the saturated box does not affect the volume of the unsaturated box.

This creates a potential problem in the representation of the unsaturated zone. The maximal possible storage in the unsaturated zone is constant and does not depend on the storage in the saturated zone. Thus, the simulated unsaturated storage is large during wet conditions, whereas in reality higher groundwater levels may reduce the volume of the unsaturated zone. In this paper a coupled formulation for saturated and unsaturated storage was presented which addresses this inconsistency and is physically more reasonable. The effect on model performance in terms of goodnessof-fit for runoff and groundwater levels was minor, but is of potential significance for hydrochemical processes in which the presence of air-filled pore space is of concern, such as redox chemistry.

Most runoff in the simulated hillslope, and in similar catchments, originates from the upper region of the saturated zone that is unsaturated during large parts of the year, see for example results from another Swedish catchment by Bishop et al. (1998). That transiently saturated zone is only converted to a saturated zone for brief periods by rising groundwater tables during runoff events. The new model explicitly accounts for the volumes of water stored in the unsaturated and saturated zone, which is of significance for future extensions to simulate runoff chemistry. A conceptually 
realistic simulation of $\delta^{18} \mathrm{O}$ would not have been possible for the hillslope under study without the unsaturated-saturated-zone coupling.

In the investigated hillslope, the groundwater dynamics of the upslope zone differed from that of the downslope, riparian zone. Conceptual models with a single groundwater reservoir or modelling approaches such as TOPMODEL that describe the groundwater level changes as a series of steady state conditions, do not represent the hydrological processes in this hillslope appropriately. Our two-box model approach captures the differences between the riparian and the upslope zone, thus laying another part of the foundation for a more realistic process representation. Subdividing the hillslope into two zones facilitated good fits between simulations and observations for both runoff and groundwater-level dynamics. The different responses to rainfall in riparian and upslope areas is assumed to be another important aspect to include in hydrological models that are to support geochemical models. A disadvantage of the proposed two-box model is that it, in order to avoid overparameterization, requires data on groundwater levels for calibration because of the increased number of parameters. At the same time, this model allows one to make more use of the groundwater-level data than would be possible for a model with a single-valued storage-runoff relationship.

Although the groundwater levels were successfully simulated in terms of Spearman rank correlation coefficients between simulated storage and mean groundwater levels for the two zones (Fig. 4), the relationship between storage and groundwater levels is not in accordance with soil properties of the hillslope. The slope of the curves showing this relationship, i.e., the change in (total) storage per unit groundwater level change, should equal the porosity. In Fig. 4 the slope gives a porosity in the riparian zone of about $10 \%$ below $0.25 \mathrm{~m}$ and a 'porosity' of more than $200 \%$ above this 
level. In the hillslope zone the groundwater table never reaches above $0.3 \mathrm{~m}$ depth and the slope below this level is constant, representing a porosity of about 70\%. These values should be compared with the observed porosity being around $30-50 \%$, with the highest values near the ground surface. Depression storage might help to explain the high 'porosity' in the riparian zone, but in general the unrealistic porosity values indicate a model fault. Tentative tests indicated that more realistic porosities could have been obtained with other parameter sets calibrated using other objective functions for the evaluation of the groundwater-levels simulations, but this was not investigated in more detail in this paper.

The simulation of stream $\delta^{18} \mathrm{O}$ was fair to acceptable. The fact that some short-term variations were missed can be interpreted as a result of neglecting any direct mixing of rainwater with streamwater and not allowing any infiltrating rainfall to by-pass the unsaturated zone. For the two smaller events on 24 and 31 August 1987 the simulated stream $\delta^{18} \mathrm{O}$ increased sharply while the observations showed a slight decrease. The simulated increase can be explained by the addition of unsaturated storage, with high $\delta^{18} \mathrm{O}$, to the saturated storage when the groundwater rose. Using a layered $\delta^{18} \mathrm{O}$ profile in the unsaturated storage instead of the simple assumption of complete mixing might improve $\delta^{18} \mathrm{O}$ simulations for these events.

Environmental tracers such as ${ }^{18} \mathrm{O}$ are often mentioned as possible tools for reducing parameter uncertainty. This study indicated that this might be too optimistic. The model structure had to be changed and new parameters had to be added. Thus, parameter values can hardly be expected to be more constrained by the $\delta^{18} \mathrm{O}$ data series. However, when a model is supposed to be used as a basis for chemical simulations, the new model structure and the additional parameters are needed 
anyway. In this case $\delta^{18} \mathrm{O}$ data series are useful to provide additional information for model calibration.

\section{Concluding remarks}

We proposed a new formulation for conceptual runoff modelling, which we argue is more reasonable. While being a more realistic description, the new model formulation is still a conceptual representation of hydrological processes. Such simple, but internally reasonable formulations are important for developing conceptual runoff models that are supposed to underpin hydrochemical models. We see the explicit consideration of the coupling and mixing between the saturated and unsaturated reservoirs as a particularly worthwhile feature of the model for future hydrochemical applications.

\section{Acknowledgments}

This work was partly performed while the first author was visiting Oregon State University. We thank Jeff McDonnell for valuable discussions. This research was partly funded by the Swedish Research Council (grant 620-20001065/2001). 


\section{References}

Bergström, S., 1995. The HBV model. In: Computer models of watershed hydrology, V.P. Singh (ed.), Water Resources Publications, Highlands Ranch, Colorado, U.S.A., 443-476.

Bergström, S., Lindström, G., 1992. Recharge and discharge areas in hydrological modelling - a new model approach. Vannet i Norden, 3: 5-12.

Beven, K.J., Lamb, R., Quinn, P., Romanowicz, R. and Freer, J., 1995. TOPMODEL. In: Computer Models of Watershed Hydrology, V.P. Singh (ed.), Water Resources Publications, Highlands Ranch, Colorado, U.S.A., 627-668.

Bishop, K.H., 1991. Episodic increase in stream acidity, catchment flow pathways and hydrograph separation. PhD thesis, University of Cambridge, U.K., 246.

Bishop, K.H., Lee, Y. H., Pettersson, C., Allard, B., 1995. Terrestrial Sources of Methylmercury in Surface Waters: The Importance of the Riparian Zone on the Svartberget Catchment. Water Air and Soil Pollut. 80: 435-444.

Bishop, K.H., Hauhs, M., Nyberg, L., Seibert, J., Moldan, F., Rodhe, A., Lange, H., Lischeid, G., 1998. The Hydrology of the Covered Catchment In: Experimental Reversal of Acid Rain Effects: The Gårdsjön Covered Catchment Experiment. H. Hultberg and R. Skeffington, (eds.) Wiley \& Sons, 109-136.

Eshleman, K.N., 1985. Hydrochemical response of a New England watershed to acid deposition. PhD thesis, M.I.T., Cambridge, MA, 180.

Harris, D. M., McDonnell, J.J., Rodhe, A., 1995. Hydrograph separation using continuous open system isotope mixing. Water Resources Research, 31(1): 157-172.

Nash, J.E., Sutcliffe, J.V. ,1970. River flow forecasting through conceptual models, part 1 - a discussion of principles, Journal of Hydrology, 10: 282-290.

Seibert, J., 1999. Conceptual runoff models - fiction or representation of reality? Acta Univ. Ups., Comprehensive Summaries of Uppsala Dissertations from the Faculty of Science and Technology 436. Uppsala. ISBN 91-554-4402-4; 52.

Seibert, J., 2000. Multi-criteria calibration of a conceptual rainfall-runoff model using a genetic algorithm. Hydrology and Earth System Sciences, 4(2): 215-224.

Seibert, J., Bishop, K., Rodhe, A., McDonnell'J.J., 2001. Groundwater dynamics along a hillslope: A test of the steady state assumption. Water Resources Research, in press

Sloan, W.T., 2000. A physics-based function for modeling transient groundwater discharge at the watershed scale. Water Resources Research, 36(1): 225241. 


\section{Figure captions}

Figure 1. The Svartberget catchment and the hillslope site.

Figure 2. Schematic structure of the two-box model with a coupled formulation for saturated and unsaturated storage. $S_{\max }$ and $S$ are maximum and actual amount of saturated storage. $U_{\max }$ is the maximum unsaturated storage based on $S$. $U$ and $U_{\min }$ are actual unsaturated storage and storage below wilting point respectively.

Figure 3. The two-box model simulations of storage in the unsaturated zone, with the riparian zone represented by solid lines, and the upslope zone by dashed lines. Manual runoff observations are shown as circles, while the runoff simulation is a solid line.

Figure 4. . Simulated saturated storage versus observed mean groundwater levels for the riparian zone (left, $r_{\text {spear }}=0.92$ ) and the upslope zone (right, $r_{\text {spear }}=0.97$ ) (note the different scale on the axes).

Figure 5. Precipitation $\delta^{18} \mathrm{O}$, with the area of the bubbles proportional to precipitation amount, hillslope runoff amount and $\delta^{18} \mathrm{O}$ calculated from stream observations are shown as circles, while the simulations of runoff and stream $\delta^{18} \mathrm{O}$ are solid lines. Consecutive precipitation samples have been bulked for $\delta^{18} \mathrm{O}$ in several cases, which causes apparently constant precipitation $\delta^{18} \mathrm{O}$ values. 


\section{Figures}

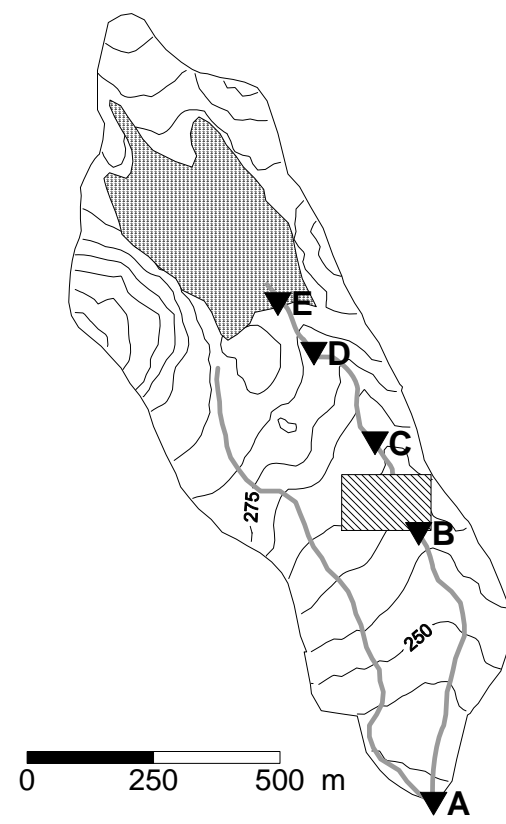

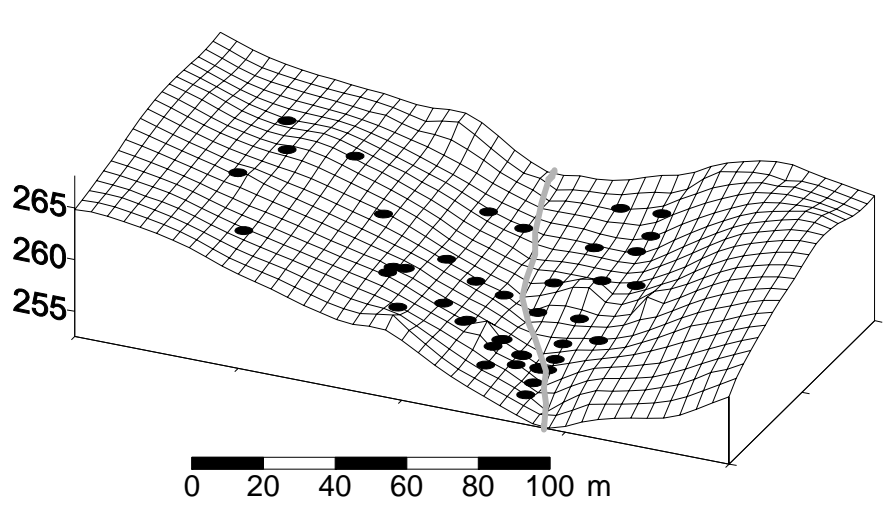

Hillslope site

Mire

Stream

$\nabla$ Weir

- Well

Figure 1. 

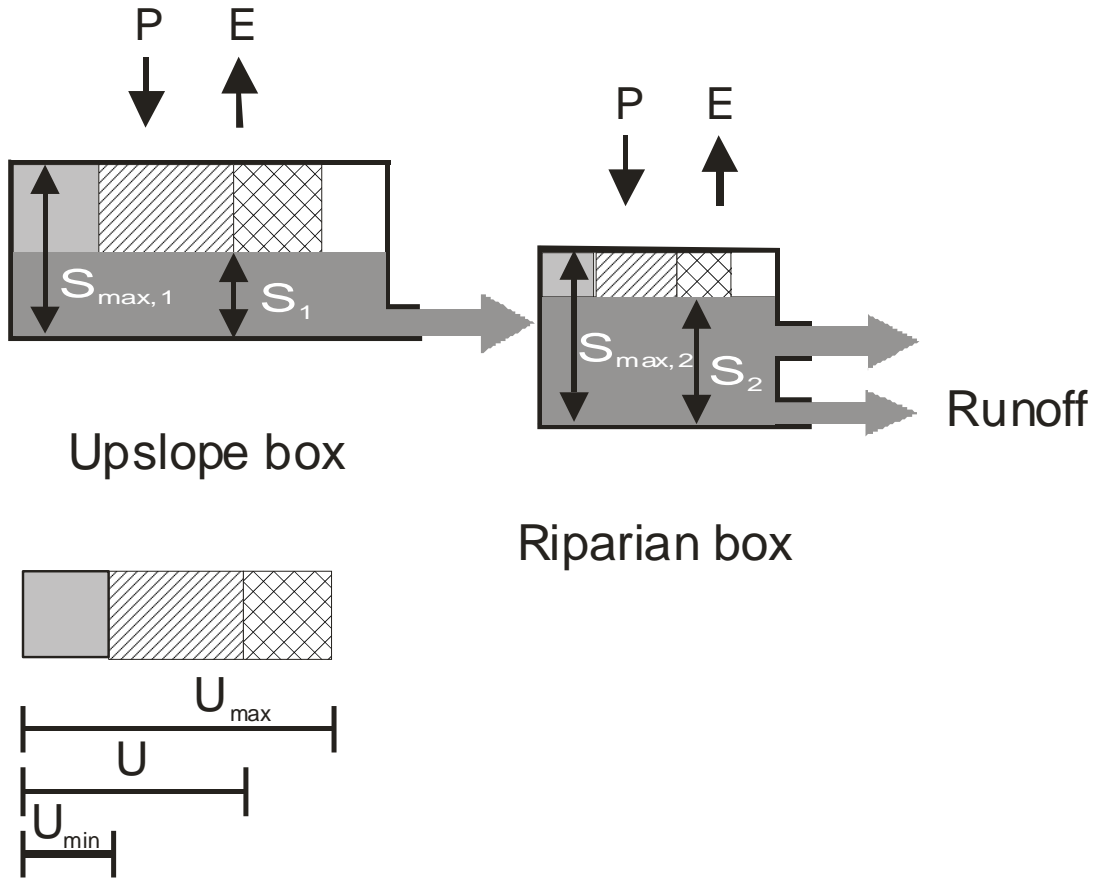

Riparian box

Fig ure 2

Figure 2. 

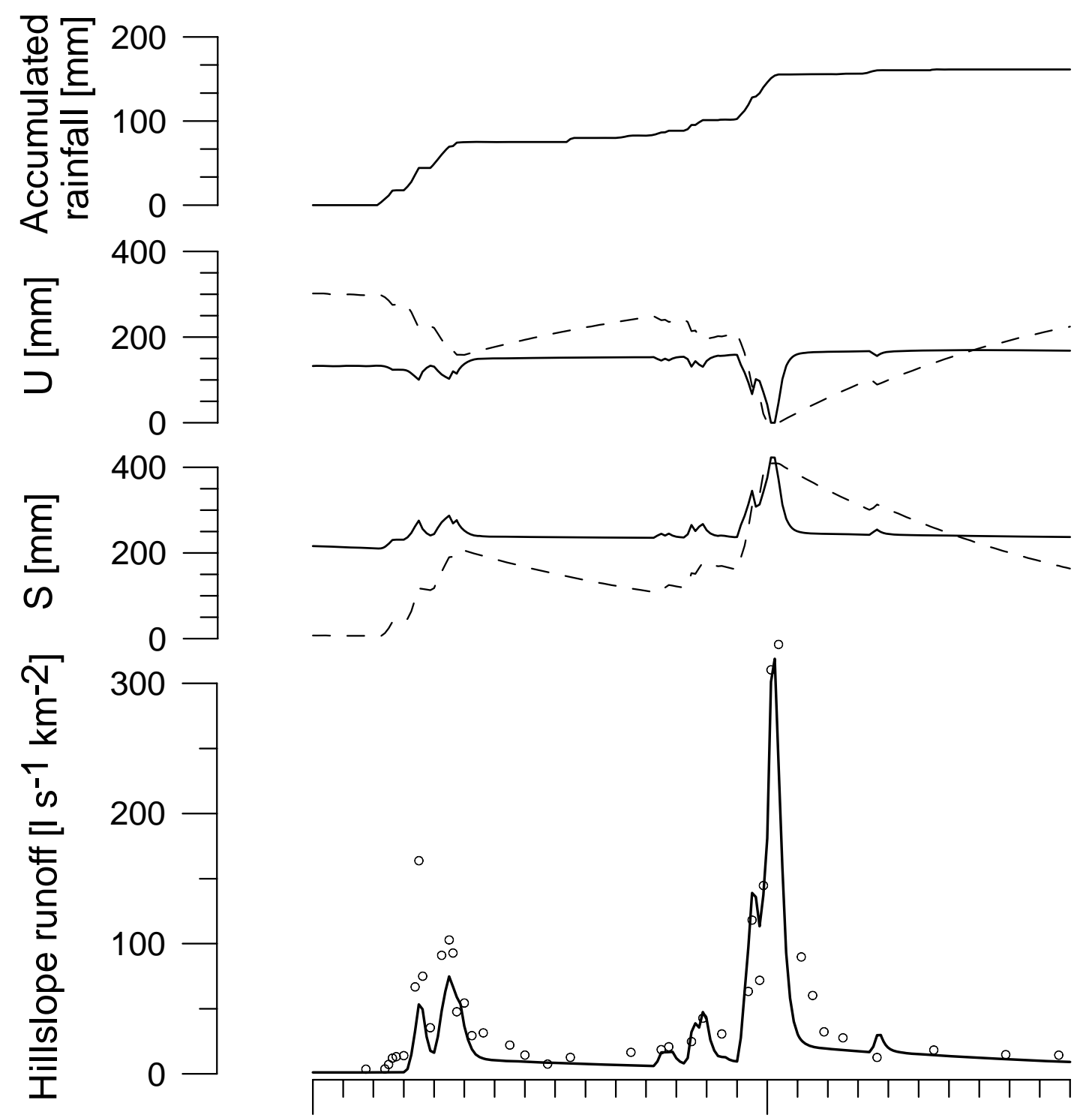

22-Jul-87

6-Aug-87

Figure 3. 

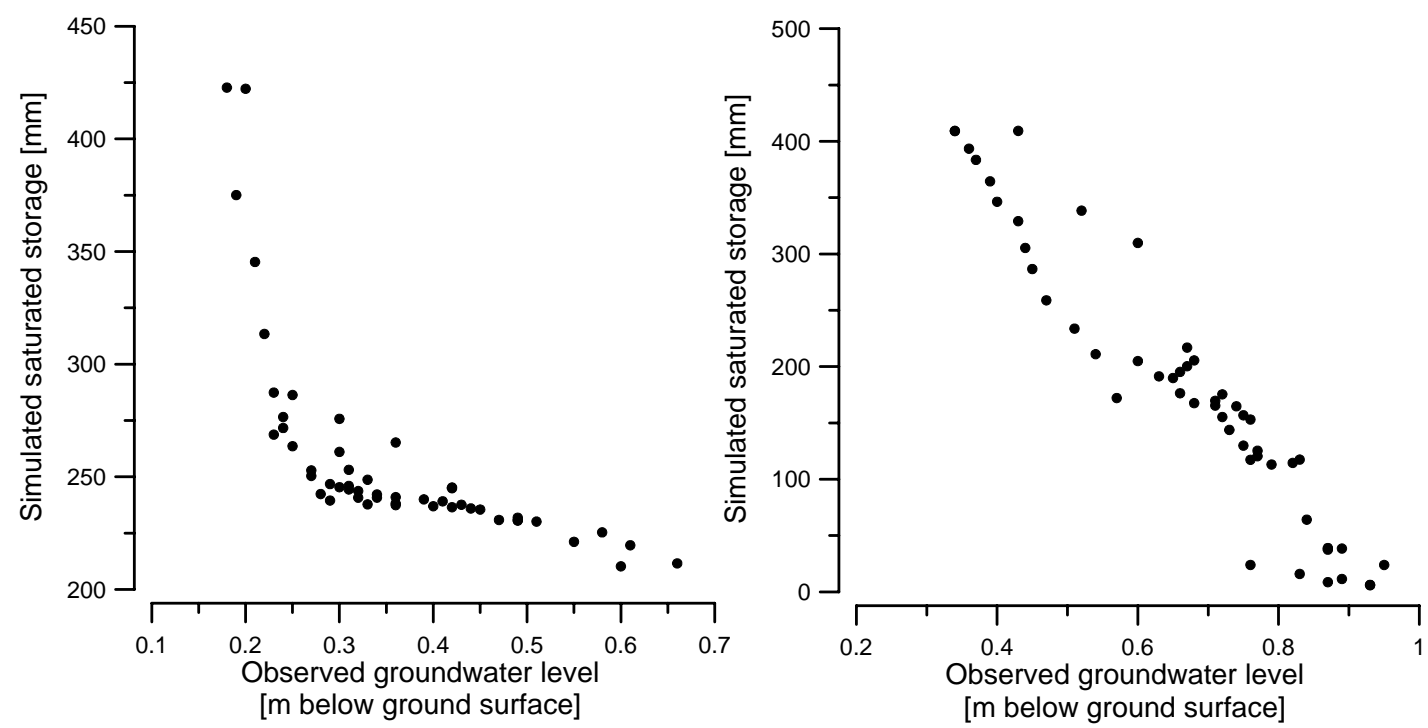

Figure 4. 


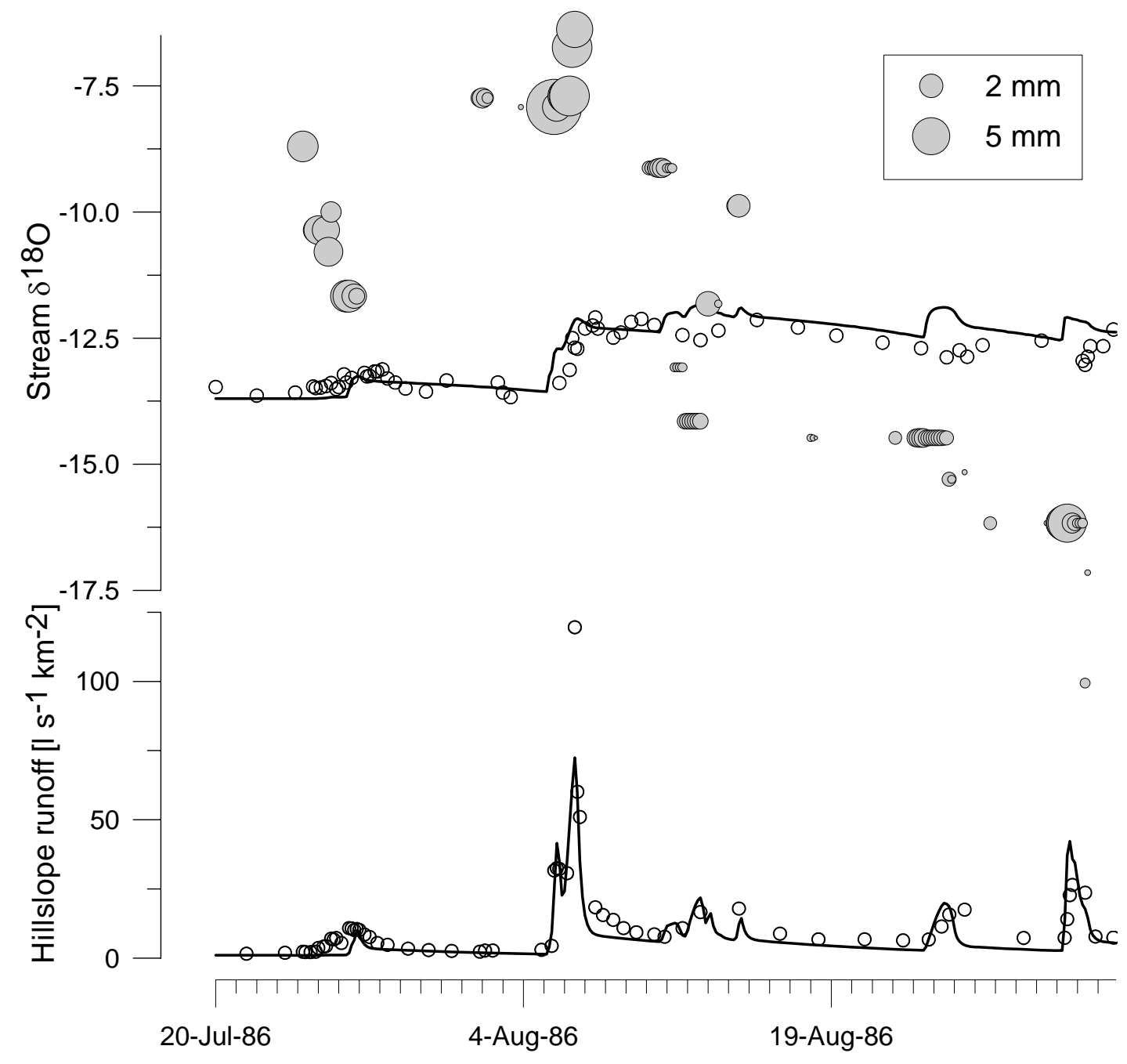

Figure 5. 
Table 1. List of parameters

\begin{tabular}{lll}
\hline Parameter & Description & Unit \\
\hline$S_{\text {max }}{ }^{a}$ & Maximal total storage & {$[\mathrm{mm}]$} \\
$c$ & $\begin{array}{l}\text { Parameter corresponding to water content at field capacity } \\
\text { divided by porosity }\end{array}$ & {$[-]$} \\
$d$ & $\begin{array}{l}\text { Parameter corresponding to water content at wilting point } \\
\text { divided by porosity }\end{array}$ & {$[-]$} \\
$\beta$ & Shape coefficient determining groundwater recharge & {$[-]$} \\
$k_{0}$ & Outflow coefficient, riparian box, upper outflow & {$\left[\mathrm{h}^{-1}\right]$} \\
$k_{1}$ & Outflow coefficient, riparian box, lower outflow & {$\left[\mathrm{h}^{-1}\right]$} \\
$S_{\text {threshold }}$ & Threshold storage for contribution from upper outflow & {$\left[\mathrm{mm}^{-1}\right]$} \\
$k_{2}$ & Outflow coefficient, upslope box & {$\left[\mathrm{h}^{-1}\right]$} \\
$p_{\text {replace }}$ & Mixing parameter for the riparian box & {$[-]$} \\
$f_{\text {riparian }}$ & Areal fraction of the riparian zone & {$[-]$} \\
$p_{\text {pcorr }}$ & Correction factor for precipitation & {$[-]$} \\
\hline
\end{tabular}

${ }^{\mathrm{a}}$ Different values were allowed for riparian/upslope box

Table 2. Goodness-of-fit for different model variants. The model variants were calibrated using two different evaluation criteria: $\left.a)\left(R_{\text {eff }}+R_{\text {eff }} \log \right) / 2, b\right)\left(R_{\text {eff }}+R_{\text {eff }} \log ^{+}\right.$ $\left.r_{\text {spear }}\right) / 3$, where $R_{\text {eff }}$ is the model efficiency, $R_{\text {eff,log }}$ is the model efficiency computed from logarithmic runoff values and $r_{\text {spear }}$ is the rank correlation coefficient for the groundwater simulations. In both cases a value of 1 corresponds to a perfect fit. The best values obtained by each calibration are given as $a$ / $b$.

\begin{tabular}{lcc}
\hline Number of boxes & \multicolumn{2}{c}{ Coupling between sat. and unsat. storage } \\
\cline { 2 - 3 } & No & Yes \\
\hline One & $0.797 / 0.831$ & $0.845 / 0.865$ \\
Two & $0.886 / 0.917$ & $0.901 / 0.924$ \\
\hline
\end{tabular}

